Journal of Technology and Science Education

\author{
$w w w . j o t s e . o r g$
}

\title{
TEACHING INNOVATION AND ITS ROLE IN CRAFTING THE CLASSROOM OF TODAY AND THE FUTURE
}

\author{
Beatriz Amante García, María Martínez Martínez
}

With constant scientific and technological evolution, it is easy to overly focus on the demands in terms of knowledge and technical competences. Along with scientific and technological knowledge, however, our educational system has to evolve to meet the specific needs of these highly technical fields, so that professionals can keep pace with the evolution in their fields and their careers.

Within the areas of engineering, sciences or humanities, teaching must include new active methodologies aiming at acquiring both specific competences and contents. However, engineering tuition involves certain pragmatics that make it the field quite distinct from other kinds of teaching domains and, hence, innovation in this area has to include specific or more adapted elements, such as PBL (Project/Problem based) methodology and Cooperative Learning (CL). Moreover, the commercial sector increasingly demands that students in this field need to acquire other generic competences as is the case of leadership, innovation and sustainability. Teachers have to consider the influence that engineering can have on and in society, a challenge that the profession has in the past largely ignored. This is an important new challenge for teachers who will have to link curriculum with generic or cross-disciplinary competences, human as well as technical values and, last but not least, teaching with human quality.

The Journal of Technology and Science Education (JOTSE) has been created as a contribution to the development and improvement of scientific and technological education by constituting a common space to share experiences to all those who, somehow, are involved in the teaching and learning processes of engineering studies, in all its modalities.

This journal aims at publishing two issues a year besides special editions. This scholarly periodical will serve as a meeting space for teaching innovation of the academic community wishing to analyse or observe methodological and pedagogical factors that may influence and enhance the learning experience of engineers. We encourage scholars in the field to submit studies that reflect specific experiences in the classroom or labs, research or projects at a national or international level, as well as broader methodological advances relevant to the field. JOTSE is backed up by the industry sector, as well as academia and broader society, and our editorial board will reflect these three domains. One issue a year will be focussed specifically on engineering teaching, while the other edition will have a broader focus.

We encourage you to use JOTSE to share your teaching experiences, research findings and project results. We look forward to hearing your suggestions for future editions, and feedback on the current edition, and we are open to cooperate with institutions and other journals and publications with common areas of interest. 